\title{
Negative contrast as a function of the interval between preshift and postshift training*
}

\author{
WILLIAM C. GORDON $\dagger$, CHARLES F. FLAHERTY $\dagger \dagger$ \\ and \\ EDWARD P. RILEY \\ Rutgers-The State University, New Brunswick, N.J. 08903
}

Rats were trained to lick either $32 \%$ or $4 \%$ sucrose solutions for $5 \mathrm{~min}$ per day. Following 10 days of acquisition training, the $32 \%$ rats were shifted to the $4 \%$ solution. A negative contrast effect was found with a 1-day hut not with a 32-day retention interval interposed between the shift phases. An attempt to reinstate the memory of the $32 \%$ solution in the 32 -day retention condition prior to the first postshift test failed to affect postshift licking behavior.

In a runway situation, rats shifted from a large to a small reward magnitude tend to run more slowly following the shift than animals trained only with the small reward (Crespi, 1942; DiLollo \& Beez, 1966). This decrement in responding, termed a successive negative contrast or depression effect, has also been demonstrated with a consummatory response measure. Rats trained to lick for a high sucrose concentration lick less when shifted to a low concentration than do animals which experience the low concentration only (Vogel, Mikulka, \& Spear, 1968; Flaherty \& Hamilton, 1971).

The occurrence of a contrast effect implies that rats remember some properties of the preshift reward (cf. Spear, 1967). Thus, by manipulating the animals' memory of prior reward, it should be possible to influence the degree to which a contrast effect occurs. A study consistent with this reasoning was reported by Gleitman \& Steinman (1964). These investigators found that the introduction of a 68-day retention interval between training with a large reward and a subsequent shift to a small reward eliminated the negative contrast effect. The failure of the contrast effect to occur was attributed to forgetting of the preshift reward magnitude, possibly because of interference between the memory of food received in the home cage and the memory of food rewards used in the runway.

In the present experiment, the effect of a 32-day retention interval on the negative contrast effect was investigated in a consummatory response situation, with sucrose solutions as rewards. The use of sucrose solutions in the experimental task should minimize the potential interference from home-cage food. The consummatory response paradigm was selected rather

*Supported by a Biological Sciences support grant and a grant from the Rutgers Research Council to the second author. This paper is sponsored by Norman Spear, who takes editorial responsibility for its contents.

+A National Institute of Mental Health predoctoral fellow. t+Requests for reprints should be sent to Charles F. Flaherty, Department of Psychology, Rutgers-The State University, New Brunswick, New Jersey 08903. than a runway task because contrast effects are apparently difficult to obtain with sucrose solutions as rewards for instrumental behavior (e.g., Rosen, 1966; Dunham \& Kilps, 1969). A second aspect of the present experiment involved an attempt to minimize the retention loss by reinstating the memory of the preshift reward during the retention interval (cf. Campbell \& Jaynes, 1966). The reinstatement treatment involved the brief exposure of some of the Ss to the original sucrose solutions at the end of the retention interval and just prior to the imposition of the shift conditions.

\section{METHOD \\ Subjects}

Twenty-six naive male Sprague-Dawley rats (Carworth Labs) were used as Ss. The rats were reduced to $80 \%$ of their $265-$ to $285-\mathrm{g}$ ad lib weight and maintained at this level by once-a-day feeding throughout the experiment.

\section{Apparatus}

Testing was conducted in three identical Plexiglas chambers $24 \mathrm{~cm}$ on each side and $20 \mathrm{~cm}$ high. The Plexiglas chambers were housed in acoustically insulated wooden boxes. Graduated drinking tubes were mounted so that the glass drinking spout was centered in a 1.4-cm hole drilled in one wall of the chamber. The orifice of the spout was $6.5 \mathrm{~cm}$ above the floor of the chamber and flush with the outside edge of the chamber wall. One side of a contact relay circuit was connected to the wire-mesh floor of each chamber, and the other side of the circuit was connected to a paper clip immersed in the solution contained in the drinking tube.

A second Plexiglas chamber, used for the reinstatement procedure, measured $25 \mathrm{~cm}$ wide and high and $30 \mathrm{~cm}$ long. The drinking spout was flush with the outside wall of the chamber and centered in a $1.5-\mathrm{cm}$-diam hole, $4 \mathrm{~cm}$ above the chamber floor. The drinking tube was mounted on a cam-operated magazine which, with associated relay programming, served to withdraw the tube from the chamber after 10 licks were made. The wiring of the contact relay circuit in the reactivation chamber was similar to the test chamber circuit.

\section{Procedure}

The Ss were assigned randomly to one of six groups defined by the factorial combination of preshift sucrose concentration (32\% and $4 \%$ ) and retention condition (1-day no reinstatement, 32-day no reinstatement, 32-day reinstatement). Five Ss were assigned to each of the reinstatement groups, four Ss to each of the other four groups. During the 10 preshift days, the procedure was identical for all retention groups. Each $S$ was placed into the test chamber and allowed 5 min access to the appropriate sucrose solution. The number of licks made in this 5 -min period was recorded. Following the test period, the $S$ was weighed, returned to its home cage, and fed its daily ration approximately $1 / 2 \mathrm{~h}$ later.

In the postshift phase, the Ss trained on the $32 \%$ solution were downshifted to $4 \%$, whereas the Ss originally trained on $4 \%$ were maintained on $4 \%$. Other aspects of the procedure were identical to the preshift phase. The downshift for the Ss in the 1-day retention condition occurred on the day following the last postshift day. The 1-day groups were run for a total of 4 postshift days. For the long retention interval groups, the first postshift test' occurred 32 days after the last preshift test day. 


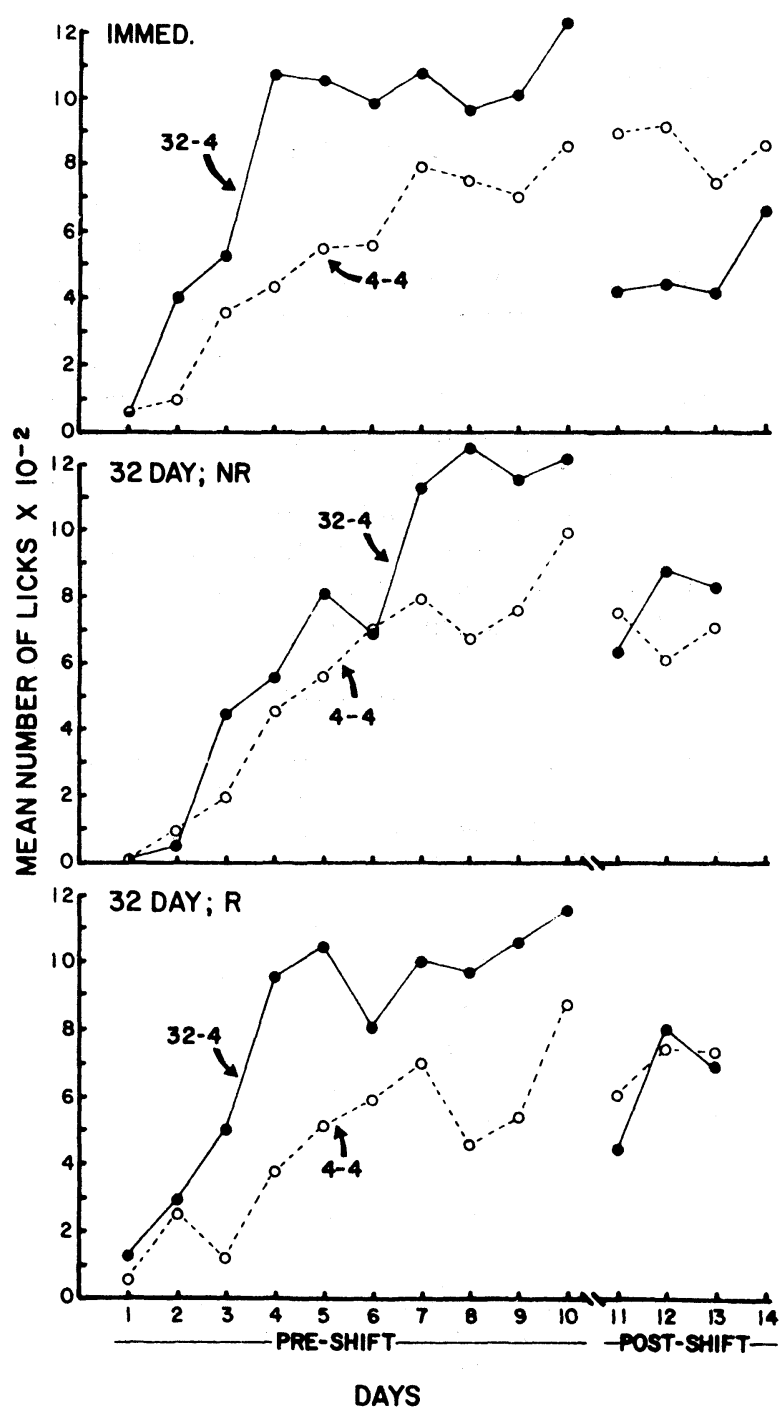

Fig. 1. Mean number of licks in $5 \mathrm{~min}$ as a function of preand postshift sucrose concentration and retention condition.

During the 32-day retention interval, the Ss were maintained at $80 \%$ of their ad lib weight and were weighed approximately every fourth day. Once postshift testing was initiated for the 32-day no-reactivation groups, the procedure was identical to that used with the 1-day groups, except that postshift testing was conducted for only 3 days. The reinstatement procedure for the 32-day reinstatement groups consisted of placing each $\mathrm{S}$ in the reinstatement chamber and allowing it access to the 32\% sucrose solution. After 10 licks of the solution were made, the drinking tube was withdrawn; the $\mathrm{S}$ was removed, immediately placed in the testing chamber, and allowed access to the $4 \%$ solution for $5 \mathrm{~min}$. Postshift testing was carried out for 3 days, but the reinstatement procedure was administered on the first day only. The sucrose solutions were prepared by weight from commercial-grade cane sugar and tap water.

\section{RESULTS}

One rat in the $4 \%$ reactivation group was dropped from the experiment for failure to lick the solution.

The mean number of licks for all groups in both phases of the experiment is presented in Fig. 1. In the preshift phase, the $32 \%$ groups licked at a higher rate than the $4 \%$ groups. This was verified statistically by an analysis of variance performed with the data from the last 2 preshift days. The analysis indicated a significant concentration effect $(F=13.8, d f=1 / 19, p<.01)$ but no significant groups effect or Groups by Concentration interaction (both Fs $<1$ ).

In the postshift phase, the rats in the 1-day group downshifted from $32 \%$ to $4 \%$ showed a decrease in licks per session to a point significantly below the unshifted $4 \%$ control group $(\mathrm{F}=7.77, \mathrm{df}=1 / 6, \mathrm{p}<.05)$. In the two retention groups, the rats downshifted from $32 \%$ to $4 \%$ sucrose following the 32-day retention period also showed a decrease in licks per session, but they dropped to the same level as the unshifted $4 \%$ group, not below it. The reinstatement and no-reinstatement groups did not appreciably differ in this regard. In both groups the postshift lick rate of shifted rats was significantly lower than the lick rate on the last 3 preshift days $(F=5.79$, $\mathrm{df}=5 / 15, \mathrm{p}<.01$ for the no-reinstatement group, and $\mathrm{F}=4.72, \mathrm{df}=5 / 20, \mathrm{p}<.05$ for the reinstatement group). The unshifted $4 \%$ controls in the 32-day no-reinstatement condition showed a slight nonsignificant drop in lick rate when the mean of the last 3 preshift days was compared to the mean of the 3 postshift days $(\mathrm{F}=3.78, \mathrm{df}=1 / 3, \mathrm{p}>.10)$. However, the unshifted $4 \%$ controls in the reinstatement condition showed a slight increase in mean lick rate (611.7 to 674.3) when the mean of the last 3 preshift days was compared to the 3 postshift days $(F=11.54, \mathrm{df}=1 / 3$, $\mathrm{p}<.05)$.

\section{DISCUSSION}

In the present experiment, shifting rats from $32 \%$ to $4 \%$ sucrose resulted in a negative contrast effect when a 1-day, but not when a 32-day, period was allowed to lapse between the preand postshift phases. These results are consistent with those found by Gleitman \& Steinman (1964) in a runway situation with a solid food reward. However, in the present experiment, it was found that the contrast effect was lost after a considerably shorter retention interval (32 days) than the 68-day retention period utilized by Gleitman \& Steinman (1964). This apparent difference in the forgetting of contrast effects may simply be an artifact of the retention periods selected in the two studies or it may actually reflect differences attributable to the task parameters of the two experiments.

In interpreting their data, Gleitman \& Steinman (1964) suggested that the loss of the contrast effect may have been due to interference between the memory of the preshift reward magnitude and the memory of the solid food given the rats in their home cages during the retention interval. In the present study, however, sucrose solutions were used as the rewards and the animals were never exposed to sucrose solutions during the retention interval or at any time outside of the experimental apparatus. The present results might still be interpreted in terms of a memory interference hypothesis (e.g., the rats performed the consummatory response of licking water in their home cages throughout the retention interval), but it does not appear that the loss of contrast depends on extraexperimental experience with the substance used as the reward.

One remaining aspect of the present data which requires mention is the failure of the reinstatement procedure to restore the contrast effect. The failure in the present experiment is 
probably due to the particular procedures and parameter values chosen. If, for example, more licks were given in the reinstatement procedure, or perhaps if several reinstatement experiences were given throughout the retention interval, then a memory conservation effect may have been obtained (cf. Campbell \& Spear, 1972).

\section{REFERENCES}

Campbell, B. A., \& Jaynes, J. Reinstatement. Psychological Review, 1966, 73, 478-480.

Campbell, B. A., \& Spear, N. E. Ontogeny of memory. Psychological Review, 1972, 79, 215-236.

Crespi, L. P. Quantitative variation in incentive and performance in the white rat. American Journal of Psychology, 1942, 55, 467-517.

DiLollo, F. D., \& Beez, V. Negative contrast effect as a function of magnitude of reward decrement. Psychonomic Science, 1966, 5, 99-100.

Dunham, D. J., \& Kilps, B. Shifts in magnitude of reinforcement: Confounded factors or contrast effects. Journal of Experimental Psychology, 1969, 79, 373-374.

Flaherty, C. F., \& Hamilton, L. W. Responsivity to decreasing sucrose concentrations following septal lesions in the rat. Physiology \& Behavior, 1971, 6, 431-437.

Gleitman, H., \& Steinman, F. Depression effect as a function of retention interval before and after shift in reward magnitude. Journal of Comparative \& Physiological Psychology, 1964, 57, 158-160.

Rosen, A. J. Incentive-shift performance as a function of magnitude and number of sucrose rewards. Journal of Comparative \& Physiological Psychology, 1966, 62, 487-490.

Spear, N. E. Retention of reinforcer magnitude. Psychological Review, 1967, 74, 216-234.

Vogel, J. R., Mikulka, P. J., \& Spear, N. E. Effects of shifts in sucrose and saccharine concentrations on licking behavior in the rat. Journal of Comparative \& Physiological Psychology, $1968,66,661-666$.

(Received for publication October 3, 1972.) 